\title{
Evolution of the interferon $\tau$ genes and their promoters, and maternal-trophoblast interactions in control of their expression
}

\author{
R. M. Roberts ${ }^{1}$, T. Ezashi ${ }^{1}$, C. S. Rosenfeld ${ }^{1,2}$, A. D. Ealy ${ }^{3}$ \\ and H. M. Kubisch ${ }^{4}$
}

'Department of Animal Science, ${ }^{2}$ Department of Veterinary Biomedical Science, University of Missouri-Columbia, Columbia, MO 65211, USA; ${ }^{3}$ Department of Dairy and Animal Science, Pennsylvania State University, University Park, PA 16802, USA; and ${ }^{4}$ Department of Veterinary Medicine, Tulane Regional Primate Research Center, Covington, LA 70433, USA

It is well established that the interferon $\tau$ (IFN- $\tau$ ) family of proteins play a major role in preventing the regression of the corpus luteum during early pregnancy in ruminants, such as cattle, sheep and goats, but not in other mammals. These interferons, which are structurally and functionally related to type I interferon, such as IF $\mathrm{N}-\alpha$ and $-\omega$, arose from a duplication of an IFN- $\omega$ gene approximately 36 million years ago. The IFN- $\tau$ genes have continued to duplicate since that time and have acquired the ability to be transcribed uniquely in the trophectoderm. Low expression is first detectable at the blastocyst stage, but massive transcriptional upregulation occurs a few days later during the initial stages of conceptus elongation. Expression is finally terminated upon trophectoderm attachment to uterine endometrium. The major promoter element that controls expression is an Ets-2/AP-1 enhancer element. Growth factors and cytokines released by the maternal endometrium that, possibly in response to progesterone, act through Ras and the mitogen-activated protein kinase (MAP-kinase) signal transduction pathway have been implicated in controlling IFN- $\tau$ gene transcription by activating Ets-2. This timely expression of IFN- $\tau$ is not only required to rescue the corpus luteum of pregnancy but may also be an indicator of conceptus fitness, thereby serving as a critical factor that dictates the continuation of pregnancy in ruminants.

\section{Introduction}

In most eutherian mammals, the functional lifespan of the corpus luteum has to be extended during pregnancy to provide continued production of progesterone and to maintain the uterine endometrium in a receptive state for conceptus development. The mechanisms used to achieve corpus luteum rescue differ markedly among groups of mammals (Roberts et al., 1996). In cattle, sheep and related pecoran ruminants, the trophoblast does not produce a 


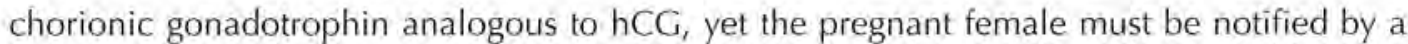
chemical signal that a conceptus is present in her uterus even before the trophoblast has attached firmly to the uterine wall. If intervention in the normal ovarian cycle does not occur, the corpus luteum will regress as a result of the action of the luteolytic hormone, prostaglandin $\mathrm{F}_{2 \alpha}\left(\mathrm{PGF}_{2 \alpha}\right)$. In a non-pregnant animal, $\mathrm{PGF}_{2 \alpha}$ is released from the uterine endometrium in a series of pulses of increasing amplitude, beginning late in the luteal phase. For the pregnancy to be successful, the conceptus must prevent luteolysis, and this intervention is accomplished by dampening $\mathrm{PGF}_{2 \alpha}$ pulsatility (Thatcher et al., 1997).

The anti-luteolytic factor responsible for rescuing the corpus luteum of cattle and sheep was shown in the 1980 s to be an interferon, now known as interferon tau (IFN- $\tau$ ) (Roberts et $a l ., 1997)$. The manner whereby IFN- $\tau$ intervenes in the normal luteolytic process has been widely reviewed (Spencer et al., 1995; Thatcher et al., 1995; Robinson et al., 1999; Demmers et al., 2001) and will not be discussed further in this study. The discovery that a cytokine was implicated as a hormone of pregnancy (Imakawa et al., 1987, 1989) caused considerable surprise and interest. By that time, interferons had been well established as potent antiviral agents and were beginning to be used therapeutically to treat viral diseases and various forms of cancer (Pestka et al., 1987; DeMaeyer and DeMaeyer-Guignard, 1988), but a role in reproduction was totally unexpected.

Interferon was first described in the 1950 s as a result of its ability to protect cells from viral infection, but remained poorly characterized for almost 25 years because the individual proteins are produced in small amounts and are active at very low concentrations (Pestka etal., 1987; DeMaeyer and DeMaeyer-Guignard, 1988). There are two main classes of interferon, still often referred to as type I and type II. IFN- $\gamma$ (type II) is an inflammatory cytokine and the product of a single gene. It has its own unique receptor and is expressed primarily by various sub-populations of activated T-lymphocytes and a restricted number of other types of cell (DeMaeyer and DeMaeyer-Guignard, 1988; Bach et al,, 1997). IFN- $\gamma$ is released in relatively large quantities by the pig trophoblast in the peri-implantation period but its functional role during pregnancy remains unknown (Lefevre et al., 1990, 1998).

The type I interferons are an extensive grouping of related genes found throughout vertebrates and include IFN $-\alpha,-\beta,-\omega$ and $-\delta$, as well as IFN- (Roberts et al., 1998). Most of the sub-types, including IFN- $\tau$, are represented by multiple genes. The three-dimensional structure of their proteins is based on a bundle of five $\alpha$-helices and a number of inter-helical loops, one of which, the AB loop, interacts extensively with the type I receptor. The hallmark of the entire grouping is their potent antiviral activity, which is usually evident at picomolar concentrations (Alexenko et al., 1997; Ealy et al., 2001). All type I interferons are pleiotrophic in action, typically possessing anti-proliferative and complex immunomodulatory as well as antiviral properties (Pestka et al., 1987; DeMaeyer and DeMaeyer-Guignard, 1988). Subtle differences in properties among individual type 1 interferons have been widely documented and are probably based on the manner in which each protein interacts with the two subunits of the common receptor to activate intracellular signal transduction pathways (Uzé et al,, 1995; Cook et al., 1996; Pestka, 2000). Nevertheless, when comparisons have been made, IFN- $\tau$ possesses the typical biological activities of other type I interferons. Importantly, there is little compelling evidence that IFN- $\tau$ is superior as an anti-luteolytic agent. IFN- $\tau$ differs most markedly from other type I interferons in the lack of inducibility of the IFN genes in response to virus, the localized expression of IFN- $\tau$ genes to one epithelial cell layer (trophectoderm), and the very high rate and persistence of IFN- p protein production over a few days at a crucial time during pregnancy when the corpus luteum is wavering on the point of regression and responsive to $\mathrm{PGF}_{2 \alpha}$ (Roberts et al., 1999). It is likely that what sets the IFN- $\tau$ proteins apart from these other interferons and has provided them with the status of hormones of pregnancy 
is their production by the conceptus in the required amounts and at the correct time to prevent regression of the corpus luteum.

The following sections discuss how the IFN- $\tau$ genes (IFNT) appear to have evolved in concert with the emergence of the ruminant ungulates, a particularly successful group of mammals. In addition, as cis-regulatory elements generally govern the onset, magnitude and timing of gene expression, the keys to understanding what makes the IFN-T uniquely different from other interferons are likely embedded in the control elements of their genes. A second focus of this review is on the unique features of IFNT promoters and the possible interplay between the conceptus and maternal uterine endometrium in governing transcriptional activity.

\section{Evolution of the IFNT}

On the basis of base substitution rates, the first IFN- $\tau$ gene (IFNT) originated by a single duplication from an IFN- $\omega$ gene (IFNW) about 36 million years ago (Roberts et al., 1997, 1998). The IFNW has been calculated to have arisen from an IFN- $\alpha$ gene (IFNA) about 130 million years ago, not long after the emergence of mammals. Hence, the IFNW is likely to be present in most orders of mammals. However, the emergence of the IFNT occurred late in mammalian evolution, well after the separation of artiodactyls (cattle, pigs, camels and their relatives) from perissodactyls (horses, rhinos and their relatives) and shortly after the pecoran ruminant suborder (Ruminantia) emerged from pigs and non-pecoran ruminants (camels, Ilamas). Consequently, IFNT, and the pregnancy recognition system that these genes orchestrate, are confined to the pecoran mammals (cattle, deer, giraffes and their relatives).

As indicated above, the interferons that are most related structurally to IF $N$ - $\tau$ are members of the IFN- $\omega$ family. The two sub-types share approximately $70 \%$ amino acid sequence identity within a species, and both have an additional six amino acids at their carboxyl termini, compared with the shorter IFN- $\alpha$ (Roberts et al., 1971, 1998). Ealy et al. (1998) have shown that this carboxyl extension is unnecessary for the anti-viral activity of the IFN-T and for their ability to extend the oestrous cycle of ewes. The most likely explanation for the longer length of the IFN- $\omega$ and $-\tau$ is that a common progenitor gene acquired an extra six codons through mutation of a stop codon. Whether this addition of six amino acids contributes to structural stability of the molecules or has some other positive advantage remains unclear.

An examination of IFNT and IFNW reveals that similarities in gene sequence disappear about 130 bases upstream of their transcription start sites and about 120 bp downstream of their stop codons, limits that might reflect the sites of the original duplication event (for further details, see Alexenko et al., 1997), which presumably occurred by homologous recombination. As there are presently no known principles governing gene duplications, the significance, if any, of the two putative break points is unclear.

There are no obvious viral control elements remaining in the IFNT promoters, whereas the IFNW lack the intact Ets-2 binding site, which is probably critical for trophoblast-specific expression (see next section). Phylogenetic analysis has been performed on the CDNA sequences of the multiple, expressed IFNT from cattle (Bos taurus) and sheep (Ovis aries) and the single genomic sequences available for musk oxen (Ovibus moschutus), goat (Capra hircus) and giraffe (Giraffida camelopardalis) (Fig. 1). The single red deer (Cervus elaphus) cDNA sequence so far described is also included in the scheme, as are the genomic sequences for two IFNW from sheep and cattle. It should be emphasized that each of the species represented by only a single gene or CDNA sequence in Fig.1 probably have many IFNT and that these genes could be as divergent as those seen in sheep. Note that the IFNT from musk ox and 


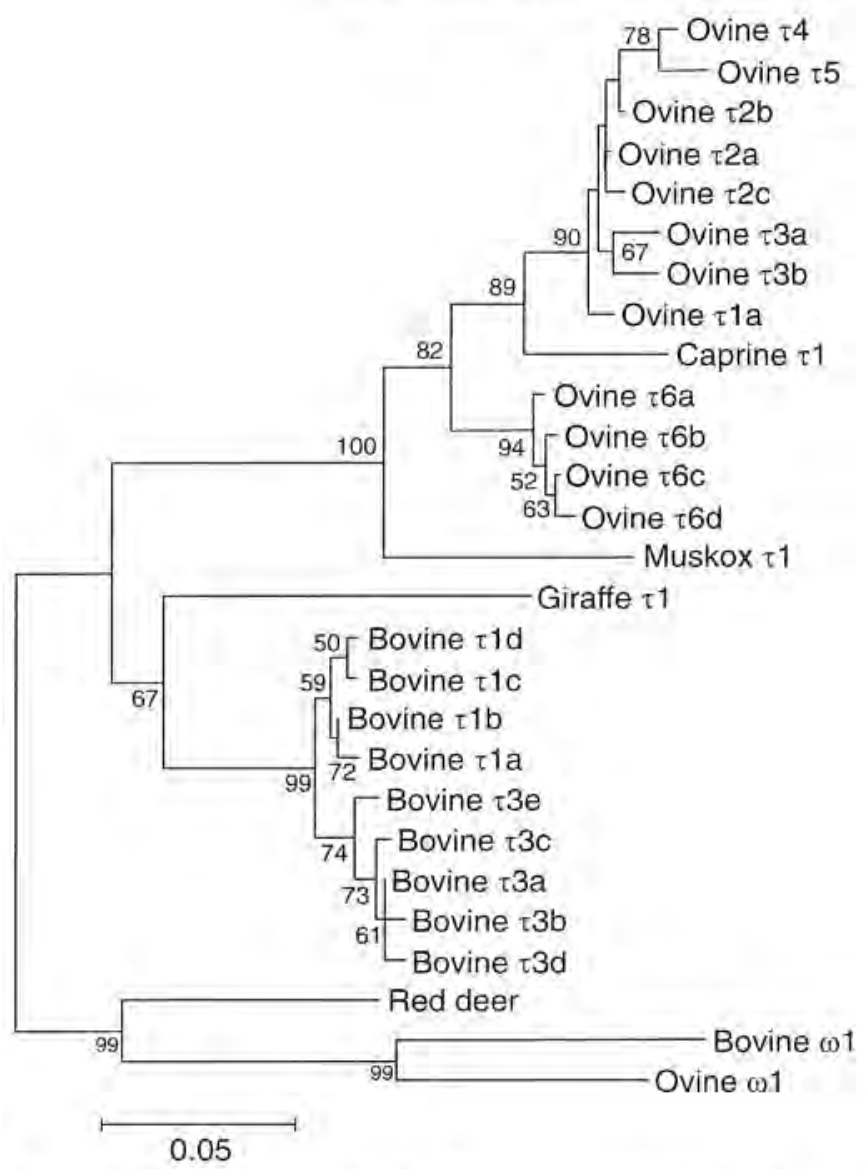

Fig. 1. A phylogenetic tree for the known interferon $\tau$ (IFN- $\tau$ ) proteins. Construction of the tree was by a neighbour joining procedure (Kumar et al., 1993) based on the proportion of amino acid differences between sequences. Signal sequences are not included in the analysis. The numbers of branches are bootstrap percentages (percentage of bootstrap pseudosamples supporting that branch). Therefore, each branch is shown with a numerical value, reflecting its reliability, except in instances where the bootstrap values were $<50 \%$ (and hence were highly unreliable). Bovine and ovine IFN- $\omega$ are included in this analysis for comparison with the IFN- $\tau$. The lengths of the branches reflect the degrees of amino acid diversity between interferons. The scale bar designates $P$ value of 0.05 . The GenBank accession numbers for sequences are M60903, M60908, M60913, M26386, M73243-M73245, AF158818AF196327, AF270471, Y00287, X56341, X56342, U55050 and AJ000638.

goat cluster with those from sheep, emphasizing the close phylogenetic relationship of these three species. The single giraffe IFNT so far cloned is well separated from the cattle and sheep genes, consistent with the early divergence of the Giraffidae from the Bovidae. Even further distanced is the cervid (red deer) cDNA sequence, which appears to display sequence features intermediate between the IFNW and IFNT of cattle. 
Many different IFN- $\tau$ cDNA have been sequenced from bovine and ovine conceptuses. In each species they fall into well-defined clusters (Fig. 1). Although it is unclear whether all the multiple forms of ovine and bovine IFN- $\tau 1$ in Fig. 1 represent different genes, as some of the minor variants present may represent polymorphic forms transcribed from the same gene locus, there is abundant evidence to indicate that many closely linked genes are present at the locus (Ryan and Womack, 1993). Moreover, the phylogenic tree shown in Fig. 1 indicates that the IFNT are continuing to duplicate at high rates. The boIFNT, which differ by $\leqslant 3 \%$ in nucleotide sequence, can be calculated to have arisen by a series of recent duplications, all occurring within the last 6-8 million years. Recent data indicate that these genes are under similar transcriptional control (Ealy et al., 2001). It remains unclear why there is a need for so many IFNT. One possibility is that the expression of several genes fulfills the requirement for large quantities of IFN-T protein. Another possibility is that there are strong selective pressures

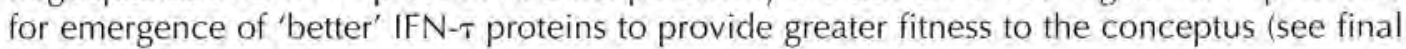
section of this paper).

\section{Transcriptional control of IFNT expression}

As stressed earlier, what sets IFN- $\tau$ apart from other type I IFN is their expression in trophoblast and their lack of responsiveness to viral induction (Cross and Roberts, 1991; Ealy et al., 2001). IFNT promoter reporter constructs are not inducible by virus, indicating that any viral response elements became disrupted as the IFNT evolved. The trophectoderm-specific expression of IFNT appears to be governed by two specific promoter regions. One region is a distal AT rich element situated approximately -358 to -322 bp from the transcription start site, which has not been studied in detail. The second is in the proximal region $(-91$ to -69$)$ of the promoter (Fig. 2). Both of these regions of the IFNT form strong associations with nuclear proteins in electrophoretic mobility shift assays performed with extracts prepared from elongating ovine and bovine trophoblast (Leaman et al., 1994). These protein-DNA associations disappear as the IFNT become downregulated a few days later. Moreover, the removal of these regions from IFNT promoters significantly reduces promoter activity. Deletion of the -91 to -61 nucleotide sequence, in particular, had a major effect, reducing basal promoter activity by $>70 \%$ (Ezashi et al., 1998).

Ezashi et al. (1998) used four tandem copies of the -91 to -69 region of the IFNT promoter as 'bait' (or target) in a yeast single-hybrid system to screen for putative transcriptional regulators in a cDNA library prepared from day 13 elongating ovine conceptuses. The transcription factor, Ets-2, bound this bait sequence, which, upon further examination, was observed to contain a close-to-consensus Ets-2 binding sequence with a central C/AGGAA/T core motif (Figs 2, 3a). Significantly, three ovine IFNT that are poorly expressed in ovine conceptuses, and are probably pseudogenes, possess IGAA rather than the conserved GGAA core sequence in this critical region of their promoters and are not Ets-2-responsive (Ezashi et al., 1998).

The choriocarcinoma cell line, JAr, has been used extensively to analyse IFNT promoter activity (Cross and Roberts, 1991; Leaman et al., 1994; Ezashi et al., 1998, 2001) because a suitable bovine cell line that can be experimentally transfected is not available. Ets-2 overexpression in JAr cells strongly upregulated bovine IFNT1 promoters as long as they contained the proximal enhancer region (Fig. $3 \mathrm{~b}$ ). In contrast, when the Ets-binding sequence on the promoter was mutated by changing the core sequence from AGGAAG to TAGTCG, both basal and Ets-2-enhanced activity was markedly reduced (Fig. 3a,b). Ezashi et al. (2001) demonstrated by western blot analysis that Ets-2 is present in JAr cells that have not been transfected with an Ets-2 expression plasmid, and it seems likely that endogenous Ets-2 


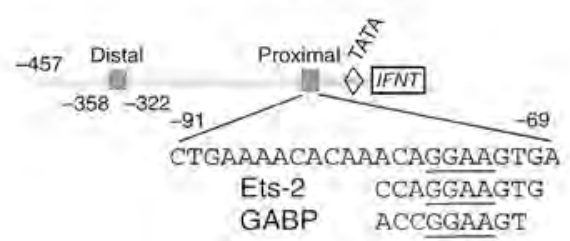

Fig. 2. A diagram of the conserved promoter sequences of the interferon $\tau$ genes (IFNT). Two regions, one distal and the other proximal, appear to bind transcription factors present in day 13 ovine conceptuses and have been implicated in transcriptional control of promoter expression. The sequence of the proximal element, containing an Ets-2 binding site, is shown. Numbers indicate base position relative to the transcription start site of the gene.

contributes to the basal IFNT promoter activity observed in the JAr cell line. Ets-2 protein can also be detected in nuclei of ovine trophectoderm cells during the period that IFN- $\tau$ is strongly expressed by conceptuses (Ezashi et al, 1998). These data indicate that the Ets-2 interaction with the proximal promoter region of IFNT is a limiting factor in IFN- $\tau$ expression in trophectoderm.

Ets-2, although a widely expressed transcription factor, seems particularly important in controlling differentiation and possibly formation of trophoblast. Not only is it a key transcription factor for several genes characteristically expressed in trophoblast, including IFNT, (Ezashi et al., 2001), but also deletion of the murine ets-2 leads to embryonic death by day 8.5 as the result of defective placental development (Yamamoto et al, 1998 ). In this context, it should be noted that mice do not possess IFN- $\tau$ genes, and that the lethality must be an outcome of effects of Ets-2 on other genes necessary for proper trophoblast development.

The production of IFN- $\tau$ by bovine and ovine conceptuses begins at the blastocyst stage, when expression on a per cell basis is very low, and begins to rise as the conceptus enlarges spherically and then begins to expand and elongate through the uterine lumen (Farin et al., 1990; Roberts et al., 1992). Conceptus elongation and hence the onset of maximal IFN- $\tau$ production is quite variable from animal to animal and appears to be correlated with the increase in maternal concentrations of serum progesterone, the hormone that controls secretory activity of endometrium (Ashworth and Bazer, 1989). We have speculated that factors in maternal uterine secretions produced in response to increasing progesterone, such as the cytokines granulocyte-macrophage colony stimulating factor (GM-CSF) and colony stimulating factor 1 (CSF-1), might upregulate IFNT expression via Ets-2. For example, luteal phase secretions from a day 15 non-pregnant ewe, when added to in vitro produced bovine blastocysts, increased the production of IFN- $\tau$ approximately threefold during the subsequent $48 \mathrm{~h}$ of culture, while having only a modest effect on the number of cells (Fig. 4). Day 12 secretions, at a similar protein concentration, were much less effective. It remains unclear why expression of IFNT continues indefinitely in cultured outgrowths of bovine blastocyst (Hernandez-Ledezma et al., 1992), whereas it is transient within the uterus. Attachment of the trophectoderm to the uterine epithelium may provide the trigger that silences gene expression (Guillomot et al., 1990). 


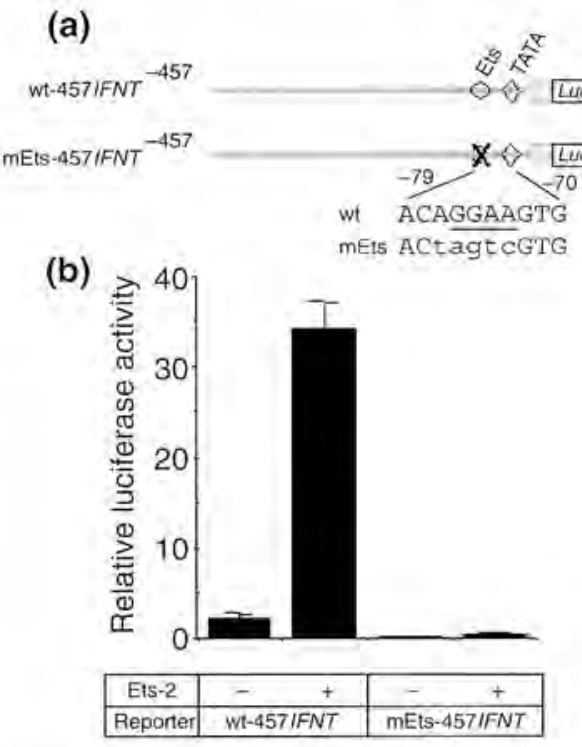

Fig. 3. Ets-2 transactivates an interferon $\tau$ gene (IFNT) promoter. (a) Sequences of the wild type and mutated Ets-2 binding sequences used in the promoter-luciferase reporter constructs for the transfection experiments are summarized in (b). (b) The wildtype -457 bovine IFNT promoter is upregulated about 35-fold by co-transfection with Ets-2 in JAr choriocarcinoma cells. By contrast both basal and Ets-2 stimulated expression from the mutated promoter is almost completely abolished. Similar results have been published by Ezashi et al. (1998), who describe the methodology in detail.

An explanation of how such factors in uterine secretions might target the Ets- 2 enhancer is currently being tested in this laboratory. It is known that certain Ras family members form an important node between cell surface receptors for certain cytokines and growth factors and downstream MAP-kinase pathways. (Fowles et al., 1998; Yordy and Muise-Helmericks, 2000). Constitutively activated Ras, for example, has an ability to increase markedly the transactivation potential of Ets- 2 by stimulating the phosphorylation of a highly conserved threonine residue (T72) in the so-called 'pointed' domain (Fig. 5a). In addition, many cellular genes, including the gene for urokinase-plasminogen activator (Stacey et al., 1995; Fowles el al., 1998; Yordy and Muise-Helmericks, 2000), have been shown to contain such Ras-responsive enhancers, which typically have an Ets-2 binding site closely juxtaposed to a binding site for AP1 (Fig. 5b,c). The production of the protease urokinase-plasminogen activator by mouse trophoblast cells temporally coincides with the invasive phase of the embryo and is concentrated in regions of invasion (Harvey et al., 1995; Sharma, 1998). Metalloproteinases, such as stromelysin, are also produced by murine trophoblast (Whiteside et al., 2001). The stromelysin promoter, for example, possesses a Ras responsive enhancer composed of two inverted Ets sites (Fig. 5b). Close examination of the IFNT proximal promoter reveals that there 
(a)

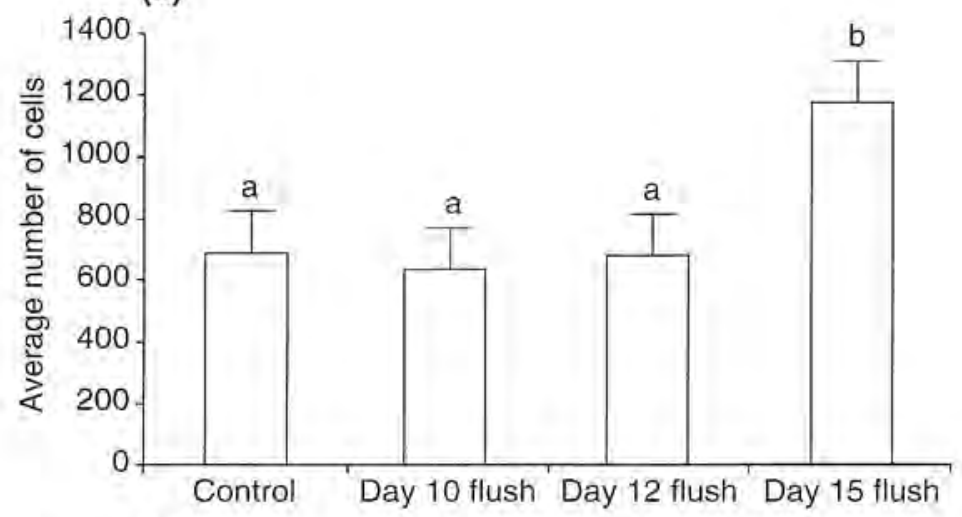

(b)

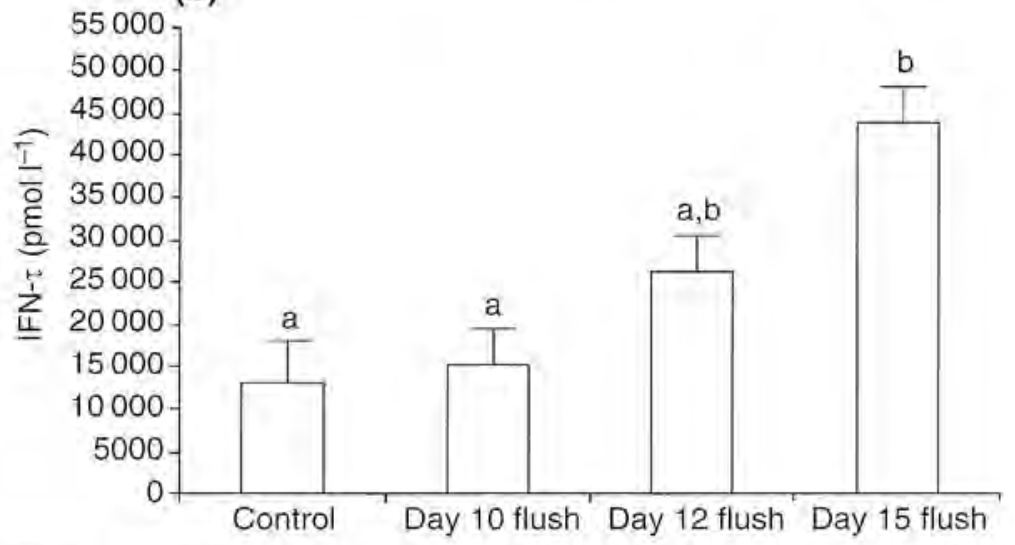

Fig. 4. The effect of addition of proteins present in uterine flushings from non-pregnant sheep at different stages of the oestrous cycle on (a) number of cells and (b) interferon $\tau$ (IFN $-\tau$ ) production from day 9 hatched bovine blastocysts cultured in vitro for $48 \mathrm{~h}$. Experimental details, including the production of blastocysts, recovery of uterine flushings, determination of the number of cells and assay of IFN, can be obtained from Kubisch et al. (2001). The data in each column of the histogram represent the mean production of IFN- $\tau \pm$ standard error from 10 blastocysts that had been cultured in individual microdrops for $48 \mathrm{~h}$, ${ }^{\mathrm{a}, \mathrm{b}} \mathrm{W}$ Where letters above columns. differ, values are significantly different $(P<0.05)$. The figure has been amended from Figs 2 and 3 of Kubisch et al. (2001) with permission.

is a close-to-consensus AP1 site adjacent to the Ets motif (Fig. $5 \mathrm{c}$ ). In a series of experiments conducted predominantly on murine $3 T 3$ cell lines (Ezashi and Roberts, 2000), which, unlike JAr cells, do not possess a constitutively active Ras component, it has been demonstrated (i) that an IFNT promoter is super-induced by expression of Ras and Ets-2 together, but not by either factor alone; (ii) that mutation of T72 on Ras partially, but not totally, reverses this effect; (iii) that mutation of the adjacent AP1 site also leads to a reduction in the ability of Ras and Ets-2 to transactivate the IFNT promoter; and (iv) that CSF-1 is able to upregulate transfected IFNT-promoter-reporter constructs in 3 T3 cell lines stably expressing the CSF-1 receptor, $c$-fms, but not in lines expressing a mutated receptor. 


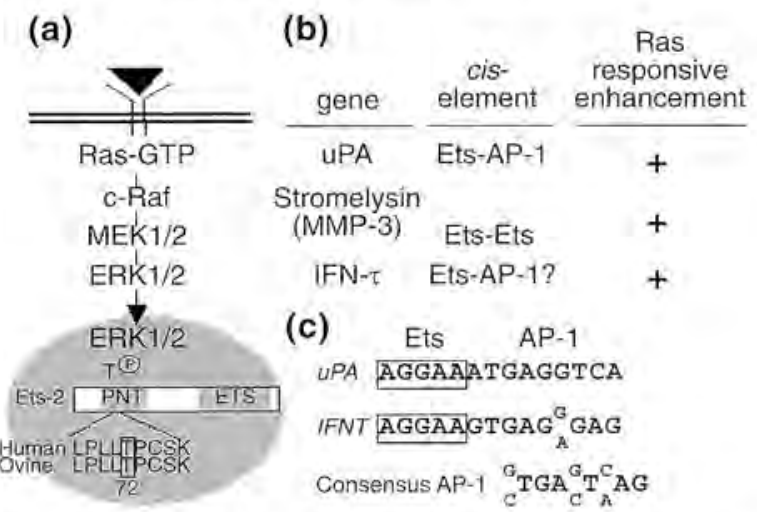

Fig. 5. The Ets-2 enhancer of the interferon $\tau$ gene (IFNT). (a) The activation of Ets-2 by the Ras/mitogenactivated protein (MAP) kinase pathway is illustrated schematically. An extracellular-ligand, such as colony stimulating factor 1 (CSF-1), binds to its receptor, which activates a branch of the MAP-kinase signal transduction pathway. The outcome of these events is the phosphorylation of a conserved Thr72 (boxed) on Ets-2, which is already bound to DNA. This modification within the Ets-2 pointed domain stimulates transcription. (b) Examples of Ets-2 enhancers that are responsive to activated Ras. Ets-2 enhancers vary widely in the manner in which they have evolved to respond to Ets-2. Some are bipartite, for example the matrix metalloproteinase 3 (MMP-3) enhancer; others, including urokinase-plasminogen activator (UPA) and possibly IFNT, have an adjacent AP1 site. (c) The putative AP1 site of IFNT is different in sequence from that of UPA, but falls within the consensus sequence for such sites.

Together, the above data indicate that the Ets-2 enhancer region of the IFNT may be required, not only for trophoblast-specific expression, but also for coordinating the responsiveness of IFNT gene expression to the maternal uterine environment.

\section{Interferon signalling: Why has it arisen?}

There is great variability within mammals in the gross morphology of the placenta, and in the manner, timing and degree to which the trophoblast breaches the uterine epithelium (Roberts et al., 1996). Therefore, it is perhaps not surprising that different groups of mammals have been forced to evolve disparate signalling mechanisms to accomplish and maintain a dialogue between the mother and her developing offspring.

Although the remarkable differences between species are apparent, it is less clear why they exist. Neither the synepitheliochorial placenta of ruminants nor the epitheliochorial placenta of pigs involve penetration of trophoblast into the endometrium or tapping of maternal blood vessels, yet they are as efficient as the haemochorial placenta of primates at delivering young. Perhaps the best explanation for explaining diversity in placental structure is that it has been driven by genetic conflict. Just as a parasite seeks new ways to avoid host defence mechanisms to exploit its host, the placenta has evolved to maximize benefits to the fetus. The mother, in turn, has devised counteracting measures to limit exploitation and to ensure her own 

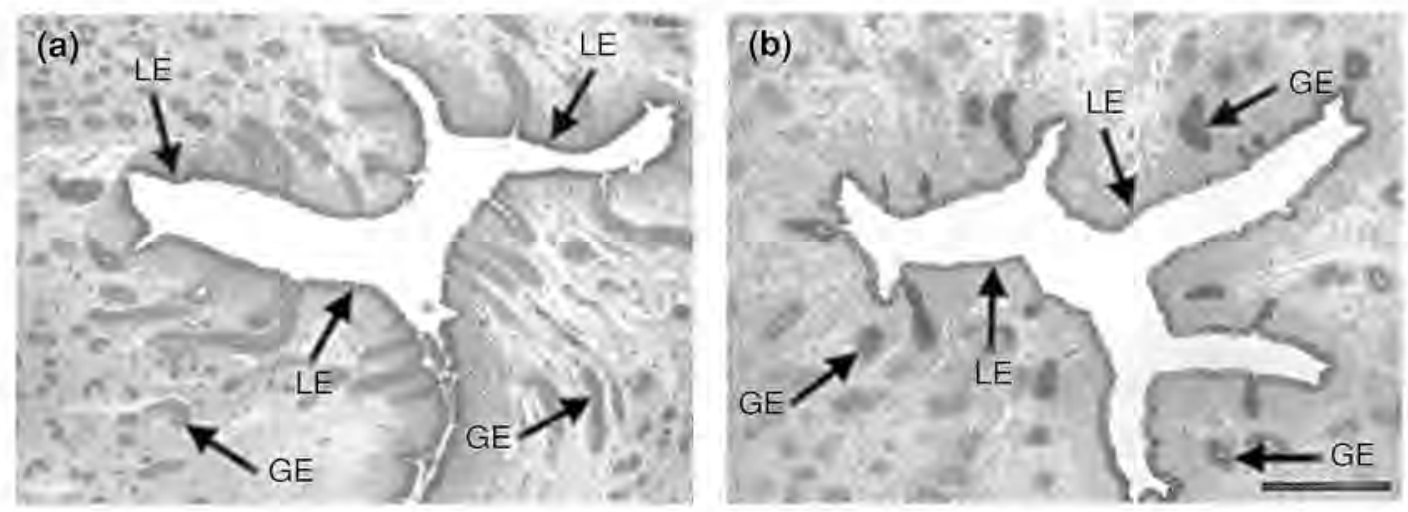

Fig. 6. Immunohistochemical localization for interferon $\alpha$ receptor (IFNAR) 1 and 2 subunits in the uteri of pregnant ewes. (a) Incubated with antiserum against IFNAR1. Arrows depict staining in luminal epithelium and glandular epithelium cells. (b) Incubated with antiserum against IFNAR2. Arrows show staining in luminal epithelium (LE) and glandular epithelium (GE) cells. (a-b) Scale bar represents $200 \mu \mathrm{m}$. The figure has been amended from Fig. 2 of Rosenfeld et al. (2002) with permission.

interests are protected. This analogy, although not wholly satisfactory because pregnancy exhibits features of both conflict and cooperation between the mother and her fetus, seems to provide the simplest explanation for why the placenta, which essentially has the same function in all mammals, should have diverged so rapidly along different branches of the evolutionary tree. This analogy should not be taken too fat. It is, after all, in the interest of the mother and fetus that neither party escalates the conflict to the extent that reproduction is compromised. We speculate that the IFN- progenitor gene presumably had an initial role in protection against viral infection and that its conversion to a conceptus signalling agent and the gradual refinement of this role involved key mutations in its promoter, which ultimately permitted expression early in trophectoderm development and subsequent massive production in response to maternal stimuli.

The fact that different trophoblast signalling mechanisms have evolved to promote similar outcomes, such as maintaining the production of progesterone from the ovary during early pregnancy, indicates that even if the cascade of events initiated by the different signals are different, the pathways achieve a similar end result. A large number of species release a luteolysin, often from the uterus and in many instances $\mathrm{PGF}_{2 \alpha}$ to terminate their ovarian cycles, yet only a few species use IFN- $\tau$ to prevent such an outcome during early pregnancy. One possible explanation is that multiple luteoprotective pathways ultimately converge on the final key steps that reduce either the synthesis or release of $\mathrm{PGF}_{2 \alpha}$. One intriguing observation is that, during early pregnancy, human and rat endometrium express several IFN- $\alpha$-responsive genes (Li et al., 2001), but human and rat conceptuses probably do not produce an IFN. Conceivably, some other cytokine, yet to be described, is responsible for upregulating these genes (Li et al., 2001). Conversely, it would not be surprising if the ruminants, although relying largely on a mechanism dependent upon IFN- to prevent luteolysis, might be expected to carry vestiges of other pathways inherited from their ancestors.

If we accept the fact that IFN- $\tau$ were co-opted as anti-luteolytic factors in association with the evolution of the synepitheliochorial placenta of the large ruminant species, another puzzle is why so much IFN is produced by the conceptus. Even in short-term culture, a single day 15 ovine conceptus produces 100-250 $\mathrm{gg}$ IFN- $\tau$ in 24 h (Ashworth and Bazer, 1989; R. M. Roberts, unpublished). Although the concentrations of IFN- $\tau$ in the uterus at about day 15 of pregnancy are difficult to estimate, they must far exceed those needed to 
saturate the type I IFN receptor ( $K_{\mathrm{d}}$ approximately $300 \mathrm{pM}$ ) (Hansen et al., 1989; Han et al., 2001), which is located predominantly on the surface and upper glandular epithelium of the maternal endometrium (Fig. 6). Could the massive output at day 15 be largely irrelevant to pregnancy outcome? One argument against this view is that uterine infusion of smaller amounts of recombinant IFN $-\tau(10 \mu \mathrm{g}$ per day, beginning on day 11 and continuing up to day 18) fails to extend luteal lifespan (Winkelman et al., 1999). Another explanation of why so much IFN- $\tau$ is produced is that it targets sites outside the uterus, although there is little evidence that it enters the systemic blood circulation, and the majority of receptors are located at sites where they are most likely to intercept IFN-T released from the conceptus (Fig. 6). There is also the possibility that the antiluteolytic events that are triggered by IFN- $\tau$ require locally high concentrations of ligand, either because the signal transduction pathway involved in dampening $\mathrm{PGF}_{2 \alpha}$ release operates optimally only at full receptor occupancy or because a non-classical receptor with high $K_{\mathrm{d}}$ is involved. Finally, it should not be overlooked that IFN- $\tau$, like hCG in the human, might be monitored by the mother as an indicator of conceptus fitness. Haig (1993) has described hCG as the 'battle cry' of the human embryo. An analogous role for IFN $-\tau$ in the ruminant species seems not to be unreasonable.

\section{References}

Alexenko AP, Leaman DW, Li J and Roberts RM (1997) The antiproliferative and antiviral activities of IFNtau variants in human cells Journal of Interferon and Cytokine Research 17 769-771

Ashworth CJ and Bazer FW (1989) Changes in ovine conceptus and endometrial function following asynchronous embryo transfer or administration of progesterone Biology of Reproduction $40425-433$

Bach EA, Aguet M and Schreiber RD (1997) The IFN-gamma receptor, a paradigm for cytokine receptor signaling Annual Review of Immunology 15 563-591

Cook JR, Cleary CM, Mariano TM, Izotova L and Pestka S (1996) Differential responsiveness of a splice variant of the human type 1 interferon receptor to interierons Journal of Biological Chemistry 271 $13448-13453$

Cross IC and Roberts RM (1991) Constitutive and trophoblast-specific expression of a class of bovine interferon genes Proceedings National Academy of Sciences USA 88 3817-3821

DeMaeyer E and DeMaeyer-Guignard J (1988) Interferons and Other Regulatory Cytokines. John Wiley and Sons, New York.

Demmers KJ, Derecka K and Flint A (2001) Trophoblast interferon and pregnancy Reproduction 121 $41-49$

Ealy AD, Green JA, Alexenko AP, Keisler DH and Roberts RM (1998) Different ovine interferon-tau genes are not expressed identically and their protein products display different activities Biology of Reproduction 58 566-573

Ealy AD, Larson SF, Liu L, Alexenko AP, Winkleman GL, Kubisch HM, Bixby JA and Roberts RM (2001) Polymorphic forms of expressed bovine interferontau genes: relative transcript abundance during early placental development, promoter sequences of genes and biological activity of protein products Endocrinology 142 2906-2915

Ezashi T and Roberts RM (2000) Colony stimulating factor-1 enhances bovine interferon-tau gene transcription via a Ras-responsive enhancer Biology of Reproduction 62289 (Abstract 464)

Ezashi T, Ealy AD, Ostrowski MC and Roberts RM (1998) Control of interferon-tau gene expression by Els-2 Proceedings National Academy of Sciences USA 95 7882-7887

Ezashi T, Ghosh D and Roberts RM (2001) Repression of Ets-2 induced transactivation of the interferon-tau promoter by Oct-4 Molecular and Cellular Biology 21 7883-7891

Farin CE, Imakawa K, Hansen TR, McDonnell JJ, Murphy CN, Farin PW and Roberts RM (1990) Expression of trophoblastic interferon genes in sheep and cattle Biology of Reproduction 43 210-218

Fowles LF, Martin ML, Nelsen L, Stacey KJ, Redd D, Clark YM, Nagamine Y, McMahon M, Hume DA and Ostrowski MC (1998) Persistent activation of mitogen-activated protein kinases p42 and p44 and Ets-2 phosphorylation in response to colonystimulating factor $1 / \mathrm{c}$-fms signaling Molecular and Cellular Biology 18 5148-5156

Guillomot M, Michel C, Gaye P, Charlier N, Trojan J and Martal J (1990) Cellular localization of an embryonic interferon, ovine trophoblastin and its mRNA in sheep embryos during early pregnancy Biology of the Cell 68 205-211

Haig D (1993) Genetic conflicts in human pregnancy Quarterly Review of Biology 68 495-532

Han C, Chen $\mathrm{Y}$ and Roberts RM (2001) Antiviral activities of the soluble extracellular domains of Type 1 
Interferon Receptors Proceedings National Academy of Sciences U/SA 98 6138-6143

Hansen TR, Kazemi M, Keisler DH, Malathy PV, Imakawa K and Roberts RM (1989) Complex binding of the embryonic interferon, ovine trophoblast protein-1, to endometrial receptors Journal of Interferon Research $9215-225$

Harvey $M$, Leco $\mathrm{KJ}$, Arcellana-Panlilio $M$, Zhang $X$, Edwards D and Schultz G (1995) Proteinase expression in early mouse embryos is regulated by leukaemia inhibitory factor and epidermal growth factor Development $1211005-11014$

Hernandez-Ledezma J, Sikes JD, Murphy CN, Watson AJ, Schultz GA and Roberts RM (1992) Expression of bovine trophoblast interferon in conceptuses derived by in vitro techniques Biology of Reproduction 47 374-380

Imakawa K, Anthony RV, Kazemi M, Marotti KR, Polites HG and Roberts RM (1987) Interferon-like sequence of ovine trophoblast protein secreted by embryonic trophectoderm Nature $330377-379$

Imakawa K, Hansen TR, Malathy PV, Anthony RV, Polites HG, Marotti KR and Roberts RM (1989) Molecular cloning and characterization of complementary deoxyribonucleic acids corresponding to bovine trophoblast protein-1: a comparison with ovine trophoblast protein-1 and bovine interferon-alphá II Molecular Endocrinology 3 $127-139$

Kubisch H, Larson M, Kiesling D and Roberts RM (2001) Control of interferon-* secretion by in vitro-derived bovine blastocysts during extended culture and outgrowth formation Molecular Reproductive Development 58 390-397

Kumar S, Tamura $K$ and Nei M (1993) MEGA: Molecular Evolutionary Genetic Analysis. Version 1.0 Pennsylvania State University, University Park

Leaman DW, Cross JC and Roberts RM (1994) Multiple regulatory elements are required to direct trophoblast interferon gene expression in choriocarcinoma cells and trophectoderm. Molecular Endocrinology 8 $456-468$

Lefevre F, Martinat-Botte F, Guillomot M, Zouari K, Charley B and La Bonnardiere C (1990) interferongamma gene and protein are spontaneously expressed by the porcine trophectoderm early in gestation European Journal of Immunology 20 2485-2490

Lefevre F, Martinat-Botte F, Locatelli A, De Niu P, Terqui $M$ and La Bonnardiere C (1998) Intrauterine infusion of high doses of pig trophoblast interferons has no antiluteolytic effect in cyclic gilts Biology of Reproduction 58 1026-1031

Li Q, Zhang M, Kumar S, Zhu L-J, Chen D, Bagchi M and Bagchi I (2001) Identification and implantation stagespecific expression of an interferon-alpha-regulated gene in human and rat endometrium Endocrinology 142 2390-2400
Pestka S (2000) The human interferon alpha species and receptors Biopolymers Review $55 \quad 254-287$

Pestka S, Langer JA, Zoon KC and Samuel CE (1987) Interferons and their actions Annual Review of Biochemistry 56 727-777

Roberts RM, Cross JC and Leaman DW (1992) Interferons as hormones of pregnancy Endocrine Reviews $13432-452$

Roberts RM, Xie S and Mathialagan N (1996) Maternal recognition of pregnancy Biology of Reproduction $54294-302$

Roberts RM, Liu L and Alexenko A (1997) New and atypical families of type 1 interferons in mammals: comparative functions, structures and evolutionary relationships Progress in Nucleic Acid Research in Molecular Biology $56287-325$

Roberts RM, Liu L, Guo Q, Leaman D and Bixby J (1998) The evolution of the type 1 interferons Erratum Journal of Interferon Cytokine Research (1999) 19 pp 427 Journal of Interferon and Cytokine Research $18805-816$

Roberts RM, Ealy AD, Alexenko AP, Han CS and Ezashi T (1999) Trophoblast interferons Placenta 20 259-264

Robinson RS, Mann GE, Lamming GE and Wathes DC (1999) The effect of pregnancy on the expression of uterine oxytocin, oestrogen and progesterone receptors during early pregnancy in the cow Journal of Endocrinology $16021-33$

Rosenfeld CS, Han C-S, Alexenko AP, Spencer TE and Roberts RM (2002) Expression of interferon receptor subunits, IFNAR1 and IFNAR2, in the ovine uterus Biology of Reproduction $67847-853$

Ryan AM and Womack JE (1993) Type I interferon genes in cattle: restriction fragment length polymorphisms, gene numbers and physical organization on bovine chromosome 8 Animal Genetics 24 9-16

Sharma R (1998) Mouse trophoblastic cell lines: IIrelationship between invasive potential and proteases In Vivo 12 209-217

Spencer TE, Becker WC, George P, Mirando MA, Ogle TF and Bazer FW (1995) Ovine interferon-tau inhibits estrogen receptor up-regulation and estrogen-induced luteolysis in cyclic ewes Journal of Endocrinology $1364932-4944$

Stacey KJ, Fowles LF, Colman MS, Ostrowski MC and Hume DA (1995) Regulation of urokinase-type plasminogen activator gene transcription by macrophage colony-stimulating factor Molecular and Cellular Biology 15 3430-3441

Thatcher WW, Meyer MD and Danet-Desnoyers G (1995) Maternal recognition of pregnancy Journal of Reproduction and Fertility Supplement 49 15-28

Thatcher WW, Binelli M, Burke I, Staples CR, Ambrose JD and Coelho S (1997) Antiluteolytic signals between conceptus and endometrium Theriogenology $47131-140$ 
Uzé G, Lutfalla G and Mogensen KE (1995) Alpha and beta interferons and their receptor and their friends and relations Journal of Interferon and Cytokine Research 15 3-26

Whiteside $E$, Jackson $M$, Herington $A$, Edwards $D$ and Harvey M (2001) Matrix metalloproteinase-9 and tissue inhibitor of metalloproteinase-3 are key regulators of extracellular matrix degradation by mouse embryos Biology of Reproduction 64 1331-1337

Winkelman G, Roberts R, Peterson J, Alexenko A and Ealy A (1999) Identification of the expressed forms of ovine interferon-tau in the pert-implantation conceptus: sequence relationships and comparative biological activities Biology of Reproduction $\mathbf{6 1}$ 1592-1600

Yamamoto $\mathrm{H}$, Flannery $\mathrm{ML}$, Kupriyanov S, Pearce I, McKercher SR, Henkel GW, Maki RA, Werb Z and Oshima RG (1998) Defective trophoblast function in mice with a targeted mutation of Ets2 Genes and Development 12 13151326

Yordy J and Muise-Helmericks R (2000) Signal transduction and the Ets family of transcription factors Oncogene 19 6503-6513 